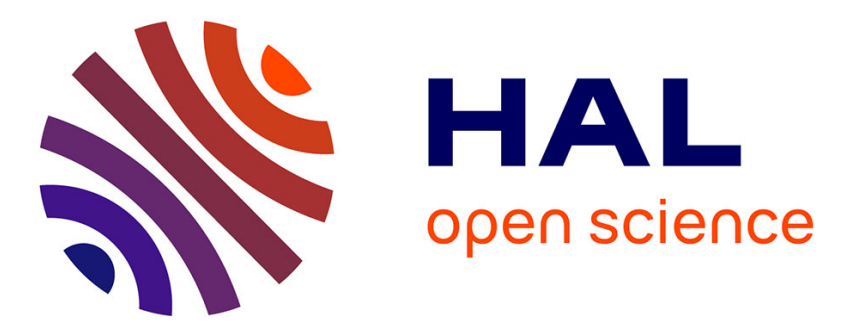

\title{
Recovery From Exercise-Induced Muscle Damage: Cold-Water Immersion Versus Whole-Body Cryotherapy
} Abd-Elbasset Abaidia, Julien Lamblin, Barthelemy Delecroix, Cédric Leduc, Alan Mccall, Mathieu Nedelec, Brian Dawson, Georges Baquet, Gregory Dupont

\section{To cite this version:}

Abd-Elbasset Abaidia, Julien Lamblin, Barthelemy Delecroix, Cédric Leduc, Alan Mccall, et al.. Recovery From Exercise-Induced Muscle Damage: Cold-Water Immersion Versus Whole-Body Cryotherapy. International Journal of Sports Physiology and Performance, 2017, 12 (3), pp.402-409. 10.1123/ijspp.2016-0186 . hal-02524887

\section{HAL Id: hal-02524887 \\ https://hal-insep.archives-ouvertes.fr/hal-02524887}

Submitted on 30 Mar 2020

HAL is a multi-disciplinary open access archive for the deposit and dissemination of scientific research documents, whether they are published or not. The documents may come from teaching and research institutions in France or abroad, or from public or private research centers.
L'archive ouverte pluridisciplinaire HAL, est destinée au dépôt et à la diffusion de documents scientifiques de niveau recherche, publiés ou non, émanant des établissements d'enseignement et de recherche français ou étrangers, des laboratoires publics ou privés. 
"Recovery From Exercise-Induced Muscle Damage: Cold Water Immersion Versus Whole Body Cryotherapy"

Note. This article will be published in a forthcoming issue of the International Journal of Sports Physiology and Performance. The article appears here in its accepted, peer-reviewed form, as it was provided by the submitting author. It has not been copyedited, proofread, or formatted by the publisher.

Section: Original Investigation

Article Title: Recovery From Exercise-Induced Muscle Damage: Cold Water Immersion Versus Whole Body Cryotherapy

Authors: Abd-Elbasset Abaïdiaa, ${ }^{1,2}$ Julien Lamblin ${ }^{2}$, Barthélémy Delecroix ${ }^{1,2}$, Cédric Leduc ${ }^{3}$, Alan McCall ${ }^{4}$, Mathieu Nédélec ${ }^{5}$, Brian Dawson ${ }^{6}$, Georges Baquet ${ }^{1}$, and Grégory Dupont ${ }^{1,2,4}$

Affiliations: ${ }^{1}$ Université de Lille, EA 7369 - URePSSS - Unité de Recherche Pluridisciplinaires Sport Santé Société, F-59000 Lille. ${ }^{2}$ Lille FC, Camphin-en-Pévèle, France. ${ }^{3}$ University of Picardie Jules Verne, Amiens, France. ${ }^{4}$ Edinburgh Napier University, Edinburgh, Scotland. ${ }^{5}$ French National Institute of Sport, Expertise and Performance (INSEP). ${ }^{6}$ University of Western Australia, Crawley, Australia.

Journal: International Journal of Sports Physiology and Performance

Acceptance Date: June 20, 2016

(C)2016 Human Kinetics, Inc.

DOI: http://dx.doi.org/10.1123/ijspp.2016-0186 
"Recovery From Exercise-Induced Muscle Damage: Cold Water Immersion Versus Whole Body Cryotherapy" by Abaïdia AE et al.

International Journal of Sports Physiology and Performance

(C) 2016 Human Kinetics, Inc.

Recovery from exercise-induced muscle damage: cold water immersion versus whole body cryotherapy

(85 characters / 85)

Submission type: Original investigation

Authors: Abd-Elbasset Abaïdia ${ }^{1,2}$, Julien Lamblin ${ }^{2}$, Barthélémy Delecroix ${ }^{1,2}$, Cédric Leduc ${ }^{3}$, Alan McCall ${ }^{4}$, Mathieu Nédélec ${ }^{5}$, Brian Dawson ${ }^{6}$, Georges Baquet ${ }^{1}$, Grégory Dupont ${ }^{1,2,4}$.

Affiliations: ${ }^{1}$ Université de Lille, EA 7369 - URePSSS - Unité de Recherche Pluridisciplinaires Sport Santé Société, F-59000 Lille. ${ }^{2}$ Lille FC, Camphin-en-Pévèle, France. ${ }^{3}$ University of Picardie Jules Verne, Amiens, France. ${ }^{4}$ Edinburgh Napier University, Edinburgh, Scotland. ${ }^{5}$ French National Institute of Sport, Expertise and Performance (INSEP). ${ }^{6}$ University of Western Australia, Crawley, Australia.

\section{Corresponding author:}

Grégory Dupont

Faculté des Sciences du Sport et de l'Education Physique

EA 7369

9, rue de l'Université

59790 Ronchin

France

Email address: gregory.dupont@univ-lille2.fr

Preferred running head: Cold-water vs whole-body cryotherapy (36 characters / 40)

Abstract word count: 236 words / 250

Text-only word count: 3484 words / 3500

Number of figures: 4

Number of tables: 2 
"Recovery From Exercise-Induced Muscle Damage: Cold Water Immersion Versus Whole Body Cryotherapy" by Abaïdia AE et al.

International Journal of Sports Physiology and Performance

(C) 2016 Human Kinetics, Inc.

\section{Abstract}

Purpose: The aim of this study was to compare the effects of cold-water immersion and whole-body cryotherapy on recovery kinetics following exercise induced muscle damage. Methods: Ten physically active men performed single-leg hamstring eccentric exercise comprising 5 sets of 15 repetitions. Immediately post-exercise, subjects were exposed in a randomized cross-over design to cold-water immersion $\left(10\right.$ minutes at $\left.10^{\circ} \mathrm{C}\right)$ or whole-body cryotherapy (3 minutes at $\left.-110^{\circ} \mathrm{C}\right)$ recovery. Creatine kinase concentrations, knee flexor eccentric $\left(60^{\circ} . \mathrm{s}^{-1}\right)$ and posterior lower limb isometric $\left(60^{\circ}\right)$ strength, single-leg and two leg countermovement jump, muscle soreness and perception of recovery were measured. The tests were performed before, immediately, $24 \mathrm{~h}, 48 \mathrm{~h}$ and $72 \mathrm{~h}$ after exercise. Results: Results showed a very likely moderate effect in favour of cold-water immersion for single-leg [Effect Size $(\mathrm{ES})=0.63 ; 90 \%$ Confidence Interval $(\mathrm{CI})=-0.13$ to $1.38 \mathrm{]}$ and two-leg countermovement jump (ES $=0.68 ; 90 \% \mathrm{CI}=-0.08$ to 1.43$) 72 \mathrm{~h}$ after exercise. Soreness was moderately lower $48 \mathrm{~h}$ after exercise following cold-water immersion $(\mathrm{ES}=-0.68 ; 90 \% \mathrm{CI}=-$ 1.44 to 0.07$)$. Perception of recovery was moderately enhanced $24 \mathrm{~h}$ after exercise for coldwater immersion $(\mathrm{ES}=-0.62 ; 90 \% \mathrm{CI}=-1.38$ to 0.13$)$. Trivial and small effects of condition were found for the other outcomes. Conclusion: Cold-water immersion was more effective in accelerating recovery kinetics than whole-body cryotherapy for countermovement jump performance at $72 \mathrm{~h}$ post-exercise. Cold-water immersion also demonstrated lower soreness and higher perceived recovery levels across $24-48 \mathrm{~h}$ post-exercise.

Key words: eccentric, muscle damage, cold-air, fatigue. 
"Recovery From Exercise-Induced Muscle Damage: Cold Water Immersion Versus Whole Body Cryotherapy" by Abaïdia AE et al.

International Journal of Sports Physiology and Performance

(C) 2016 Human Kinetics, Inc.

\section{Introduction}

Cooling the body to accelerate the recovery of performance is now widely used by coaches and athletes. ${ }^{1}$ One of the theoretical bases of cooling the body to accelerate recovery is a decrease in inflammation due to exposure to the cold environment. ${ }^{2,3}$ Inflammation occurs immediately following exercise induced muscle damage and is prolonged over time. ${ }^{4}$ Although this inflammatory response is required to heal muscle damage, ${ }^{4}$ an attenuation of this inflammation may have beneficial effects on recovery of muscle performance. ${ }^{2}$

The principle of cold-water immersion (CWI) is to immerse a part, or all of the body (except the head) in a cold-water bath in which the temperature is below $15^{\circ} \mathrm{C}$ for a duration of 10 to 12 minutes. ${ }^{5}$ In contrast, whole-body cryotherapy (WBC) consists of body exposure to very-cold air at a temperature between $-110^{\circ} \mathrm{C}$ to $-195^{\circ} \mathrm{C}$ in a specifically designed room, for a total duration of 3 to 4 minutes. $^{3}$

Studies have shown the ability of CWI to improve strength and power recovery kinetics following exercise induced muscle damage in comparison with a passive recovery. ${ }^{6}$

Similarly, Hausswirth et al. ${ }^{7}$ and Ferreira-Junior et al. ${ }^{8}$ found a beneficial effect of WBC on recovery kinetics in comparison with far-infrared and passive recovery conditions, respectively. Two systems are frequently used for whole-body cryotherapy: cold air ${ }^{7}$ or liquid nitrogen. ${ }^{8}$ In the cold-air system, the chamber is closed and subjects have to traverse a first room at a temperature of $-10^{\circ} \mathrm{C}$. They traversed a second room at a temperature of $-60^{\circ} \mathrm{C}$. and stay 3 minutes in a room at a temperature of $-110^{\circ} \mathrm{C}$. In the liquid nitrogen system subjects are exposed 3 minutes at a temperature of $-110^{\circ} \mathrm{C}$. In this system the head is not exposed to cold.

CWI and WBC have a significant effect on reducing some biological markers of muscle damage ${ }^{3,9}$ and inflammation. ${ }^{3}$ Additionally, these recovery strategies have also been shown to provide a beneficial effect on subjectively perceived soreness the day after 
"Recovery From Exercise-Induced Muscle Damage: Cold Water Immersion Versus Whole Body Cryotherapy" by Abaïdia AE et al.

International Journal of Sports Physiology and Performance

(C) 2016 Human Kinetics, Inc.

exercise. ${ }^{9,6}$ However, the efficacy of CWI is not clearly established despite the large volume of research performed in this area. ${ }^{9}$ Roberts et al. ${ }^{10}$ found that regular post-exercise CWI may attenuate muscular adaptations to resistance training.

In a meta-analysis, Poppendieck et al. ${ }^{11}$ compared the effects on recovery of CWI versus WBC. They found a slightly higher average effect size on performance recovery for CWI. However, in this review only two studies regarding WBC effects on recovery kinetics were reported. Differences between CWI or WBC protocols make the comparison between both recovery strategies difficult. Parameters such as magnitude of strength loss following the exercise implemented or the type of exercise task used vary from one study to another. ${ }^{8,12}$ To the best of our knowledge, no study has compared CWI with WBC for effects on muscle performance recovery kinetics, biochemical markers of muscle damage and perceived soreness. Therefore, the aim of this study was to compare the effects of cold-water immersion and whole-body cryotherapy on recovery kinetics following exercise induced muscle damage.

\section{Methods}

\section{Experimental design}

In a randomized crossover design, subjects performed 5 sets of 15 eccentric knee flexors contractions on one leg to induce muscle damage. Immediately after, subjects performed either a CWI or a WBC recovery session. Each session was separated by two weeks. Subjects performed a battery of tests before the exercise (baseline values), immediately after (0h), and $24 \mathrm{~h}, 48 \mathrm{~h}$ and $72 \mathrm{~h}$ after the exercise induced muscle damage.

\section{$\underline{\text { Subjects }}$}

Of the fourteen initial participants, four subjects were excluded: two incurred an injury and two did not respect the inclusive criteria. Ten physically active men (age: $23.4 \pm 4$ 
"Recovery From Exercise-Induced Muscle Damage: Cold Water Immersion Versus Whole Body Cryotherapy" by Abaïdia AE et al.

International Journal of Sports Physiology and Performance

(C) 2016 Human Kinetics, Inc.

years; height: $178 \pm 9 \mathrm{~cm}$; body mass: $73.4 \pm 12.0 \mathrm{~kg}$ ) participated in this study: they had not incurred any hamstring injury during the prior six months. Subjects were asked not to undertake any physical activity at least 48 hours prior to the completion of the first test (baseline). They were instructed not to perform any physical activity, not to consume protein, alcohol or caffeine nor to perform any recovery strategies in the 24 hours before the exercise inducing muscle damage and also during the 3 days following the exercise. The level of hamstring soreness and the level of fatigue had to be lower than 5 (moderately sore/tired) on a 0 to 10 point scale $(0=$ not sore; $10=$ very, very sore $)$ and $(0=$ not tired; $10=$ very, very tired), respectively. Each subject answered a questionnaire before each session to check if these criteria were respected. If the participants did not respect these inclusion criteria they were excluded from the study. All subjects provided written informed consent to participate to this study. This study was made in accordance with the local ethical committee on biomedical research $\left(\mathrm{N}^{\circ} 5915052012\right)$ and the standards set by the Declaration of Helsinki.

\section{Methodology}

Subjects' allocation: Subjects were allocated in a randomized and balanced order to both conditions: CWI and WBC. Dominant and non-dominant legs were assigned to a condition in a randomized and balanced order. The order of recovery session was also randomized and 4 combinations were used: non-dominant leg + CWI, dominant leg + CWI, non-dominant leg + WBC, dominant leg + WBC. Randomization of participants was conducted by using a random-numbers generator (www.randomization.com) to assign subjects to their groups. To avoid cross adaptation consequences of the contralateral leg on force values and recovery kinetics ${ }^{13}$ half of the group started with CWI and the other half with WBC. 
"Recovery From Exercise-Induced Muscle Damage: Cold Water Immersion Versus Whole Body Cryotherapy" by Abaïdia AE et al.

International Journal of Sports Physiology and Performance

(C) 2016 Human Kinetics, Inc.

Familiarization and tests: Subjects performed two sessions of familiarization consisting of 5 repetitions of the test at a low intensity and two repetitions at a maximal intensity. Two sessions were performed to determine the level of reliability for eccentric force, isometric force and CMJ-1L tests. Reliability statistics were calculated between trial 1 and trial 2 (table 1) at the baseline time point. Trial 1 and trial 2 were separated by $72 \mathrm{~h}$. Baseline values were recorded before the experimental protocol. During each session, the investigator verbally encouraged subjects to perform at their best. Encouragements were standardized. Each session was preceded by a standardized warm-up.

Warm-up: The warm-up comprised 2 sets of 10 repetitions of concentric contractions with one-minute recovery between sets on an isokinetic dynamometer (Con-Trex MJ, CMV AG, Dübendorf, Switzerland). The subjects performed knee flexions at $60^{\circ} \cdot \mathrm{s}^{-1}$ at a fixed intensity of $60 \mathrm{~N} \cdot \mathrm{m}^{-1}$.

Exercise-induced muscle damage: Subjects performed a hamstring exercise (knee flexion) task using the tested leg on an isokinetic dynamometer (as above). The exercise task comprised 5 sets of 15 eccentric contractions at a speed of $60^{\circ} . \mathrm{s}^{-1}$, interspersed by a 3 minute recovery. Each contraction lasted 3 seconds and recovery time between contractions lasted 3 seconds.

Subjects were seated on the dynamometer chair, with the hip joint at $75^{\circ}$. Full extension of the leg was considered as $0^{\circ}$ for dynamic tests (range of motion $0-90^{\circ}$ ). The distal shin pad of the dynamometer was attached $3-4 \mathrm{~cm}$ proximal to the lateral malleolus by using a strap. During muscle contractions, to minimize extraneous body movements, straps were applied across the chest, pelvis and mid-thigh. The alignment between the dynamometer rotational axis and the knee joint rotation axis (lateral femoral condyle) was checked at the beginning of each trial. Gravity's effect on torque was recorded on each subject throughout the range of motion, and this was used to correct torque measurements during all tests. The 
"Recovery From Exercise-Induced Muscle Damage: Cold Water Immersion Versus Whole Body Cryotherapy" by Abaïdia AE et al.

International Journal of Sports Physiology and Performance

(c) 2016 Human Kinetics, Inc.

isokinetic dynamometer was calibrated according to the recommendations of the manufacturer. Thirty minutes after completing exercise the subjects noted the global intensity using the modified rate of perception scale from 0 (rest) to 10 (maximal). ${ }^{14}$

Recovery sessions: These took place 5 minutes after the last test was performed, which corresponds to $0 \mathrm{~h}$ after the exercise task. During CWI, in a standing position, subjects wore swimming trunks and were immersed up to the neck in a cold-water pool at $10^{\circ} \mathrm{C}$ for 10 minutes. ${ }^{5}$ During WBC subjects were in a cryocabin (Cryo Sana, Mecacel, France) producing cold air from liquid nitrogen at a temperature of $-110^{\circ} \mathrm{C}$ for 3 minutes. ${ }^{8}$ Skin was directly exposed to cold except the head (which was outside the top of the cabin) and the hands and feet while inside the cabin, were protected by gloves, socks and clogs. Exercise and recovery sessions were performed in a room with a temperature of $21^{\circ} \mathrm{C}$.

Force tests: Subjects were tested on an isokinetic dynamometer (as above) in knee flexion at different speeds and on different types of muscular contractions: eccentric force $\left(60^{\circ} . \mathrm{s}^{-1}\right)$ and isometric force $\left(5\right.$ seconds at $\left.60^{\circ}\right)$. Subjects performed two trials interspersed by three-minute recovery for each kind of contraction. Force was tested immediately postexercise $(0 \mathrm{~h})$, then at $24 \mathrm{~h}, 48 \mathrm{~h}$ and $72 \mathrm{~h}$ post-exercise.

Single-leg $(C M J-1 L)$ and two-legs $(C M J-2 L)$ countermovement jump: Subjects performed the jumps on a force plate (Kistler Instruments, Hampshire, UK). They kept the foot of the tested leg in contact with the platform, with their hands on the hips. Their knee was flexed to a self-selected depth in response to the instruction to jump as high as possible, and to land on the same leg. The platform was calibrated according to the manufacturer recommendations. Single leg countermovement jump was performed before CMJ-2L. Subjects performed two trials interspersed by one-minute recovery for each kind of jump. For CMJ-2L, Nedelec et al. ${ }^{15}$ found a high reliability. The typical error was $1.5 \mathrm{~cm}$, the intra-class correlation coefficient 0.92 and the coefficient of variation $2.9 \%$. Test re-test reliability of 
"Recovery From Exercise-Induced Muscle Damage: Cold Water Immersion Versus Whole Body Cryotherapy" by Abaïdia AE et al.

International Journal of Sports Physiology and Performance

(C) 2016 Human Kinetics, Inc.

CMJ-1L is presented in table 1 . The typical error was $0.85 \mathrm{~cm}(90 \% \mathrm{CI}=0.5$ to 2.5$)$, the intraclass correlation coefficient $0.97(90 \% \mathrm{CI}=0.8$ to 0.99$)$ and the coefficient of variation $9.4 \%$. Single-leg and two-leg countermovement jumps were assessed immediately post-exercise (0h), then $24 \mathrm{~h}, 48 \mathrm{~h}$ and $72 \mathrm{~h}$ post-exercise.

Creatine kinase: Blood samples were taken from $32 \mu$ fingertip capillary punctures to assess plasma creatine kinase concentrations [CK]. Blood was placed on a measurement strip and analyses were done using a Reflotron (Roche Diagnostics, Grenzacherstrasse, Switzerland). The Reflotron was calibrated according to the manufacturer recommendations. Previous work by Horder et al. ${ }^{16}$ showed a between-day coefficient of variation of $4.2 \%$ for $[\mathrm{CK}]$ measures with the Reflotron. Plasma $[\mathrm{CK}]$ was measured before exercise, then $24 \mathrm{~h}, 48 \mathrm{~h}$ and $72 \mathrm{~h}$ post-exercise.

Muscle soreness and Perceived recovery: Subjects were asked to rate their level of perceived hamstring muscle soreness using a Likert scale from 0 (not sore) to 10 (very, very sore). ${ }^{17}$ Subjects rated their level of perceived recovery using a recovery scale from 0 (very well recovered) to 10 (very poorly recovered). The scale used here was adapted from Laurent et al., ${ }^{18}$ who established this scale, but with an inverse number order (i.e. 0 was "very poorly recovered"). The numbers were changed here to achieve coherence between the recovery and soreness scales (i.e. from positive to negative perception). Muscle soreness was rated preexercise, immediately post-exercise (0h: before the recovery session), then $24 \mathrm{~h}, 48 \mathrm{~h}$ and $72 \mathrm{~h}$ after exercise. Perceived recovery was rated immediately post-exercise (0h: after the recovery session), then $24 \mathrm{~h}, 48 \mathrm{~h}$ and $72 \mathrm{~h}$ after exercise.

\section{$\underline{\text { Statistical analysis }}$}

Data are presented as mean \pm standard deviation $(\mathrm{SD})$. Values for force, CMJ-1L, CMJ-2L and $[\mathrm{CK}]$ were normalized to $100 \%$. A small effect size was found for the difference 
"Recovery From Exercise-Induced Muscle Damage: Cold Water Immersion Versus Whole Body Cryotherapy" by Abaïdia AE et al.

International Journal of Sports Physiology and Performance

(C) 2016 Human Kinetics, Inc.

of the baseline values between CWI and WBC for all outcomes. The effect of time and the effect of condition on the dependent variables - force, CMJ-1L, CMJ-2L, [CK], soreness and perceived recovery- were analysed using the following criteria: $\geq 0$ to $\leq 0.2=$ trivial; 0.21 to $\leq 0.6=$ small $; 0.61$ to $\leq 1.2=$ moderate $; 1.21$ to $\leq 2=$ large $; 2.1$ to $\leq 4=$ very large; $\geq 4=$ nearly perfect. ${ }^{19}$ To calculate the effect size, the mean difference was defined as CWI value WBC value for all the outcomes. Confidence interval (CI) was set at 90\%. Probability to have a higher effect of a condition compared to the other was assessed qualitatively as follows: $<0.5 \%$, most unlikely or almost certainly not; $0.5-5 \%$, very unlikely; $5.1-25 \%$, unlikely or probably not; $25.1-75 \%$, possibly; $75.1-95 \%$, likely or probably; $95.1-99.5 \%$, very likely; $>99.5 \%$, most likely or almost certainly. If the probability to have results in favour of both treatments were $>5 \%$, the true difference was assessed as unclear. ${ }^{20}$ The percentage of chance is presented in favour of: cold-water immersion/trivial/whole-body cryotherapy. For reliability of eccentric force, isometric force, and CMJ-1L the coefficient of variation $(\mathrm{CV})$, intraclass correlation coefficient (ICC), 90\% confidence intervals (CI) and typical error (TE) were calculated. ${ }^{21}$

\section{Results}

\section{$\underline{\text { Rate of perceived exertion }}$}

A trivial effect size $(-0.09 ; 90 \% \mathrm{CI}=-0.96$ to 0.79$)$ was found for the difference of mean RPE collected after exercise for the CWI condition $(6.3 \pm 2.4)$ and the WBC condition $(6.5 \pm 2.1)$.

Reliability

Interday test-retest reliability for eccentric force, isometric force and CMJ-1L was calculated. Results are presented in Table 1. 
"Recovery From Exercise-Induced Muscle Damage: Cold Water Immersion Versus Whole Body Cryotherapy" by Abaïdia AE et al.

International Journal of Sports Physiology and Performance

(c) 2016 Human Kinetics, Inc.

\section{Time effect}

Effect sizes and $90 \%$ CI of each time point in comparison with baseline values are presented in Table 2 for eccentric force, isometric force, CMJ-2L, CMJ-1L, soreness, perception of recovery and $[\mathrm{CK}]$ for each condition. A large to very large effect of time was found for all the outcomes across the $72 \mathrm{~h}$ except CMJ-1L 72h post exercise and [CK] $48 \mathrm{~h}$ post-exercise. Figures 1 to 4 display the change over time for the different variables.

\section{Condition effect}

Effect sizes and 90\% CI of between-condition effect are presented in Figures 1 to 4. Probabilities of chances to have an effect in favour of a condition are also presented in figures 1 to 4 for eccentric force, isometric force, $\mathrm{CMJ}-2 \mathrm{~L}, \mathrm{CMJ}-1 \mathrm{~L}$, soreness, perception of recovery and $[\mathrm{CK}]$. An effect of condition was found in favour of CWI for CMJ-1L and CMJ-2L 72h post-exercise (figure 2), muscle soreness $48 \mathrm{~h}$ post-exercise and perceived recovery $24 \mathrm{~h}$ postexercise (figure 3). Creatine kinase concentrations were largely and moderately lowered in the CWI condition in comparison with the WBC condition $24 \mathrm{~h}$ and $72 \mathrm{~h}$ after exercise, respectively.

\section{Discussion}

The aim of this study was to compare the effects of cold-water immersion and wholebody cryotherapy on recovery kinetics following exercise induced muscle damage. Results showed that, in comparison with WBC, a very likely moderate effect in favour of CWI was evident for accelerating CMJ-1L and CMJ-2L recovery $72 \mathrm{~h}$ after exercise. In addition, a likely moderate effect in favour of CWI was found for lower muscle soreness $48 \mathrm{~h}$ after exercise and better perceived recovery $24 \mathrm{~h}$ after exercise. A very likely large effect and a likely moderate effect in favour of CWI were found for lower [CK] $24 \mathrm{~h}$ and $72 \mathrm{~h}$ after 
"Recovery From Exercise-Induced Muscle Damage: Cold Water Immersion Versus Whole Body Cryotherapy"

by Abaïdia AE et al.

International Journal of Sports Physiology and Performance

(C) 2016 Human Kinetics, Inc.

exercise, respectively. For eccentric and isometric force development the effect was unclear across $72 \mathrm{~h}$ of recovery.

For this experiment to be useful, it was important to establish that the exercise task chosen did induce significant muscle damage. Muscle force loss is considered to be one of the best tools for quantifying muscle damage. ${ }^{22}$ The results confirm the effectiveness of the chosen exercise task, as large to very large effects of time in both conditions were reported in force decrement (Table 2). Height of CMJ-2L was also affected by the exercise in both recovery conditions, as large to very large effects of time were found. This effect was less pronounced in single leg jumps, as a moderate time effect was detected for CMJ-1L across the $72 \mathrm{~h}$ post-exercise recovery period in the WBC condition, and moderate to large time effects only up to $48 \mathrm{~h}$ post-exercise in the CWI condition. Nevertheless, sufficiently high force and jump performance decrements were noted across $72 \mathrm{~h}$ of recovery, to allow an assessment of the effectiveness of the two recovery procedures.

When comparing the conditions, CWI was found more likely to improve recovery kinetics of CMJ-1L and CMJ-2L at 72h post-exercise. Muscle power recovery assessed from CMJ-1L and CMJ-2L was faster following CWI than WBC. The larger effect of CWI on recovery kinetics could be partly explained by the rate of heat transfer $(\mathrm{Q})$. Water $(0.58$ $\mathrm{W} /(\mathrm{m}-\mathrm{K})$ has a 24.2 times higher heat-transfer coefficient $(\mathrm{k})$ than air $(0.024 \mathrm{~W} /(\mathrm{m}-\mathrm{K})$ : as such, water is more efficient for extracting heat energy from the body than air. ${ }^{23}$ In further contrast to cold-air, cold-water exerts a hydrostatic pressure on the body. ${ }^{2}$ Previous work has found that CWI and hot-water immersion are both effective in improving muscle strength recovery in comparison with passive recovery, but CWI is more effective than hot-water immersion. ${ }^{24}$ Together, these data indicate that the combination of cold and hydrostatic pressure may act together to improve performance recovery kinetics. It can be hypothesized that the faster recovery kinetics with cold-water immersion may be at least partially linked 
"Recovery From Exercise-Induced Muscle Damage: Cold Water Immersion Versus Whole Body Cryotherapy" by Abaïdia AE et al.

International Journal of Sports Physiology and Performance

(c) 2016 Human Kinetics, Inc.

with the capacity of water to extract heat combined with the hydrostatic pressure. Cold-water immersion is more effective than hot water immersion in accelerating muscle recovery ${ }^{24}$ indicating that cold may be a factor that accelerates muscle recovery. Water $(0.58 \mathrm{~W} /(\mathrm{m}-\mathrm{K})$ has a 24.2 times higher heat-transfer coefficient $(\mathrm{k})$ than air $\left(0.024 \mathrm{~W} /(\mathrm{m}-\mathrm{K})^{23}\right.$ and CWI may decrease skin temperature for a longer duration than WBC. As recovery kinetics of muscular force were not different between CWI and WBC, one can suggest that CWI enhanced speed recovery faster than $\mathrm{WBC}$.

Whole-body cryotherapy and cold-water immersion have both demonstrated the ability to decrease muscle soreness across $72 \mathrm{~h}$ post-exercise. ${ }^{6,25}$ The results suggest that CWI was more effective in decreasing muscle soreness at $48 \mathrm{~h}$ post-exercise, and that perceived recovery was higher at $24 \mathrm{~h}$ after exercise. These findings are consistent with a recent metaanalysis $^{6}$ that reported a lower general fatigue after exercise for subjects using CWI in comparison with passive recovery. With regard to potential mechanisms, Algafly and George $^{26}$ found that pain threshold and pain tolerance were increased and nerve conduction velocity of the tibial nerve was reduced following direct ice application on the ankle. Applying pressure with compression garments to muscles has also been shown to decrease perceived muscle soreness. ${ }^{27}$ As cold-water can decrease skin temperature for a longer period than air $^{29}$ and also exerts a pressure on the body, ${ }^{2}$ it can be hypothesized that this longer temperature decrease combined with the pressure exerted by water may have also increased pain tolerance.

Similar to other studies, ${ }^{7}[\mathrm{CK}]$ increased after the muscle damaging exercise. A large effect of time was found $24 \mathrm{~h}$ and $72 \mathrm{~h}$ post-exercise and a moderate effect of time was found $48 \mathrm{~h}$ post-exercise in the CWI condition. Very large and large effects were found $24 \mathrm{~h}, 48 \mathrm{~h}$ and $72 \mathrm{~h}$ post-exercise, respectively, in the WBC condition. For the condition effect, a very likely 
"Recovery From Exercise-Induced Muscle Damage: Cold Water Immersion Versus Whole Body Cryotherapy"

by Abaïdia AE et al.

International Journal of Sports Physiology and Performance

(C) 2016 Human Kinetics, Inc.

large effect and a likely moderate effect in favour of CWI, respectively $24 \mathrm{~h}$ and $72 \mathrm{~h}$ postexercise, suggesting a higher effectiveness of CWI in comparison with WBC.

\section{Limitations}

This study presents some limitations. Firstly, the sample size was too small for some of the variables studied._A statistical power test was performed, retrospectively, for the following variables: eccentric force $($ power $=1)$, isometric force $($ power $=1), \mathrm{CMJ}-1 \mathrm{~L}$ (power $=0.18$ ), and CMJ-2L (power $=0.35$ ). Secondly, due to the cross-over design and the fact that subjects performed a single-leg exercise, it was not possible to implement a true control condition. Having a control condition would have allowed an analysis of the efficiency of each recovery procedure in comparison with a passive recovery. Thirdly, muscle and skin temperatures were not measured in this study, and may have provided useful information on the heat exchange afforded by each recovery procedure. According to the study of Costello et al., ${ }^{28}$ who compared vastus lateralis and thigh skin temperature decrease between CWI ( 4 minutes at $\left.8^{\circ} \mathrm{C}\right)$ and WBC $\left(20\right.$ seconds at $-60^{\circ} \mathrm{C}$ and 3 minutes and 40 seconds at $\left.-110^{\circ} \mathrm{C}\right)$, a $2^{\circ} \mathrm{C}$-drop in muscle temperature $(3 \mathrm{~cm}$ below the subcutaneous fat layer) can be expected 60 minutes after exposure in both conditions. In the CWI condition a $9^{\circ} \mathrm{C}$-drop in skin temperature can be expected immediately after exposure and a $5^{\circ} \mathrm{C}$-drop can be expected 60 minutes after exposure. In the WBC condition a $12^{\circ} \mathrm{C}$-drop can be expected immediately after exposure and a $4{ }^{\circ} \mathrm{C}$-drop can be expected 60 minutes after exposure. The amplitude of confidence intervals obtained for force were very large, spanning all levels of magnitude and potentially leading to unclear results. ${ }^{20}$ 
"Recovery From Exercise-Induced Muscle Damage: Cold Water Immersion Versus Whole Body Cryotherapy" by Abaïdia AE et al.

International Journal of Sports Physiology and Performance

(C) 2016 Human Kinetics, Inc.

\section{Practical applications}

This study shows that, in this hamstring damaging protocol, using CWI was more beneficial than WBC to improve muscle power recovery $72 \mathrm{~h}$ after the exercise. Implementing CWI is a potentially useful strategy to accelerate recovery after an exercise inducing muscledamage.

\section{Conclusion}

To our knowledge this study is the first to directly compare CWI and WBC effects on performance recovery following exercise induced muscle damage. The results showed that CWI may be more efficient in accelerating recovery kinetics than WBC for single-leg and two-leg countermovement jumps at $72 \mathrm{~h}$ post-exercise. Although no differences in strength recovery were found between the two procedures, CWI did lower ratings of muscle soreness and increase perceived recovery across $24-48 \mathrm{~h}$ post-exercise. In perspective, it would be interested to study the effects of both strategies for repeated treatments at $24 \mathrm{~h}$ and $48 \mathrm{~h}$ postexercise on recovery kinetics and the repeated bout effect.

\section{Acknowledgements}

The authors gratefully acknowledge all the subjects who participated in this study.

\section{Conflict of interest}

The authors have no conflicts of interest that are directly or indirectly relevant to the content of this article. No financial support was provided for this study. 
"Recovery From Exercise-Induced Muscle Damage: Cold Water Immersion Versus Whole Body Cryotherapy" by Abaïdia AE et al.

International Journal of Sports Physiology and Performance

(C) 2016 Human Kinetics, Inc.

\section{References}

1. Nédélec M, McCall A, Carling C, Legall F, Berthoin S, Dupont G. Recovery in soccer: part II-recovery strategies. Sports Med. 2013a;43(1):9-22.

2. Wilcock IM, Cronin JB, Hing WA. Physiological response to water immersion: a method for sport recovery? Sports Med. 2006;36(9):747-65.

3. Banfi G, Lombardi G, Colombini A and Melegati G. Whole-body cryotherapy in athletes. Sports Med. 2010;40(6):509-517.

4. Clarkson PM, Hubal MJ. Exercise-induced muscle damage in humans. Am J Phys Med Rehabil. 2002;81(11 Suppl):S52-69.

5. Versey NG, Halson SL, Dawson BT. Water immersion recovery for athletes: effect on exercise performance and practical recommendations. Sports Med. 2013;43(11):110130.

6. Bleakley C, McDonough S, Gardner E, Baxter GD, Hopkins JT, Davison GW. Cold-water immersion (cryotherapy) for preventing and treating muscle soreness after exercise. Cochrane Database Syst Rev. 2012;15;2:CD008262.

7. Hausswirth C, Louis J, Bieuzen F, Pournot H, Fournier J, et al. Effects of whole-body cryotherapy vs. far-infrared vs. passive modalities on recovery from exercise-induced muscle damage in highly-trained runners. PLoS ONE 2011;6(12): e27749.

8. Ferreira-Junior JB, Bottaro M, Vieira A, Siqueira AF, Vieira CA, Durigan JL, Cadore EL, Coelho LG, Simões HG, Bemben MG. One session of partial-body cryotherapy ($110^{\circ} \mathrm{C}$ ) improves muscle damage recovery. Scand J Med Sci Sports. 2015;25(5):e524-30.

9. Leeder J, Gissane C, van Someren K, Gregson W, Howatson G. Cold water immersion and recovery from strenuous exercise: a meta-analysis. Br J Sports Med. 2012;46(4):23340.

10. Roberts LA, Raastad T, Markworth JF, Figueiredo VC, Egner IM, Shield A, CameronSmith D, Coombes JS, Peake JM. Post-exercise cold water immersion attenuates acute anabolic signalling and long-term adaptations in muscle to strength training. $J$ Physiol. 2015;593(18):4285-301.

11. Poppendieck W, Faude O, Wegmann M, Meyer T. Cooling and performance recovery of trained athletes: a meta-analytical review. Int $J$ Sports Physiol Perform. 2013;8(3):227-42.

12. Bailey DM, Erith SJ, Griffin PJ, Dowson A, Brewer DS, Gant N, Williams C. Influence of cold-water immersion on indices of muscle damage following prolonged intermittent shuttle running. J Sports Sci. 2007;25(11):1163-70.

13. Starbuck C, Eston RG. Exercise-induced muscle damage and the repeated bout effect: evidence for cross transfer. Eur J Appl Physiol. 2012;112(3):1005-13. 
"Recovery From Exercise-Induced Muscle Damage: Cold Water Immersion Versus Whole Body Cryotherapy"

by Abaïdia AE et al.

International Journal of Sports Physiology and Performance

(C) 2016 Human Kinetics, Inc.

14. Foster C, Florhaug JA, Franklin J, Gottschall L, Hrovatin LA, Parker S, Doleshal P, Dodge C. A new approach to monitoring exercise training. J Strength Cond Res. 2001;15(1):109-15.

15. Nédélec M, McCall A, Carling C, Le Gall F, Berthoin S, Dupont G. Physical performance and subjective ratings after a soccer-specific exercise simulation: comparison of natural grass versus artificial turf. J Sports Sci. 2013b;31(5):529-36.

16. Hørder M, Jørgensen PJ, Hafkenscheid JC, Carstensen CA, Bachmann C, Bauer K, Neuwald C, Rosalki SB, Foo AY, Vogt W. Creatine kinase determination: a European evaluation of the creatine kinase determination in serum, plasma and whole blood with the Reflotron system. Eur J Clin Chem Clin Biochem. 1991;29(10):691-6.

17. Thompson D, Nicholas CW, Williams C. Muscular soreness following prolonged intermittent high-intensity shuttle running. J Sports Sci. 1999;17(5):387-95.

18. Laurent, CM, Green, JM, Bishop, PA, Sjo“ kvist, J, Schumacker, RE, Richardson, MT, and Curtner-Smith, M. A practical approach to monitoring recovery: development of a perceived recovery status scale. J Strength Cond Res. 2011;25(3): 620-628.

19. Hopkins, WG. A scale of magnitudes for effect statistics. In: A New view of Statistics, 2002a. Available at http: //www.sportsci.org/resource/stats/effectmag.html. Accessed 15 April, 2015.

20. Batterham AM, Hopkins WG. Making meaningful inferences about magnitudes. Int J Sports Physiol Perform. 2006;1(1):50-7.

21. Hopkins, WG. Precision of measurement. In: A new view of Statistics, 2002b. Available at http: //www.sportsci.org/resource/stats/precision.html. Accessed 15 April, 2015.

22. Warren GL, Lowe DA, Armstrong RB. Measurement tools used in the study of eccentric contraction-induced injury. Sports Med. 1999;27(1):43-59.

23. Bleakley CM, Bieuzen F, Davison GW, Costello JT. Whole-body cryotherapy: empirical evidence and theoretical perspectives. Open Access J Sports Med. 2014;10;5:25-36.

24. Vaile J, Halson S, Gill N, Dawson B. Effect of hydrotherapy on the signs and symptoms of delayed onset muscle soreness. Eur J Appl Physiol. 2008;102(4):447-55.

25. Costello JT, Baker PR, Minett GM, Bieuzen F, Stewart IB, Bleakley C. Whole-body cryotherapy (extreme cold air exposure) for preventing and treating muscle soreness after exercise in adults. Cochrane Database Syst Rev. 2015;18;9:CD010789.

26. Algafly AA, George KP. The effect of cryotherapy on nerve conduction velocity, pain threshold and pain tolerance. Br J Sports Med. 2007;41(6):365-9.

27. Hill J, Howatson G, van Someren K, Leeder J, Pedlar C. Compression garments and recovery from exercise-induced muscle damage: a meta-analysis. $\mathrm{Br}$ J Sports Med. 2014;48(18):1340-6.

28. Costello JT, Culligan K, Selfe J, Donnelly AE. Muscle, skin and core temperature after $110^{\circ} \mathrm{c}$ cold air and $8^{\circ} \mathrm{c}$ water treatment. PLoS One. 2012;7(11):e48190. 
"Recovery From Exercise-Induced Muscle Damage: Cold Water Immersion Versus Whole Body Cryotherapy" by Abaïdia AE et al.

International Journal of Sports Physiology and Performance

(C) 2016 Human Kinetics, Inc.
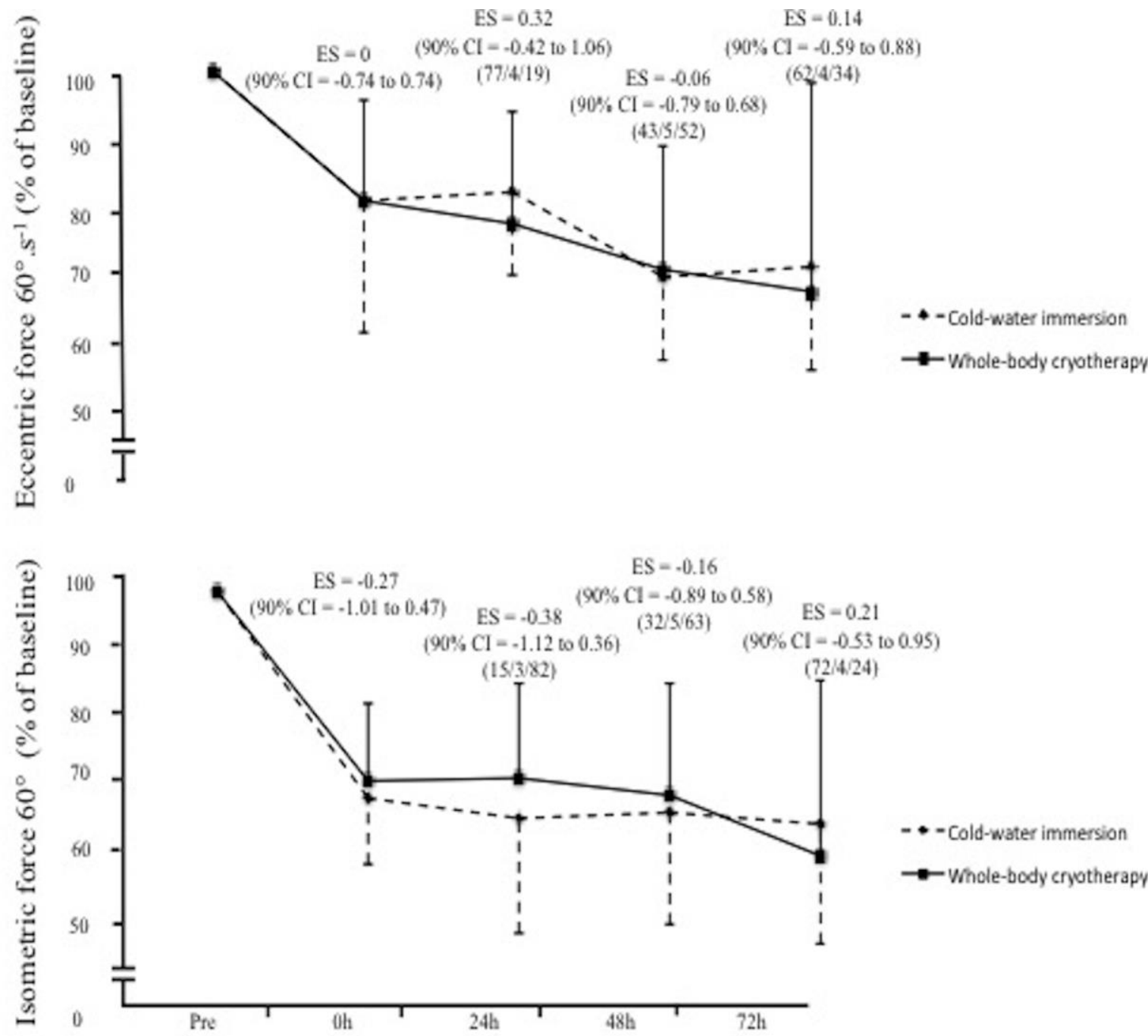

Figure 1: Time-evolution of eccentric force at $60^{\circ}$.s- 1 and isometric force at $60^{\circ}$ in the coldwater and whole-body cryotherapy conditions at baseline (Pre), immediately (0h), 24h, 48h and $72 \mathrm{~h}$ after the exercise induced muscle damage. ES = effect size between cold-water and whole-body cryotherapy. Probabilities to have an effect are presented as: (cold-water immersion/trivial/whole-body cryotherapy). 
"Recovery From Exercise-Induced Muscle Damage: Cold Water Immersion Versus Whole Body Cryotherapy" by Abaïdia AE et al.

International Journal of Sports Physiology and Performance

(c) 2016 Human Kinetics, Inc.
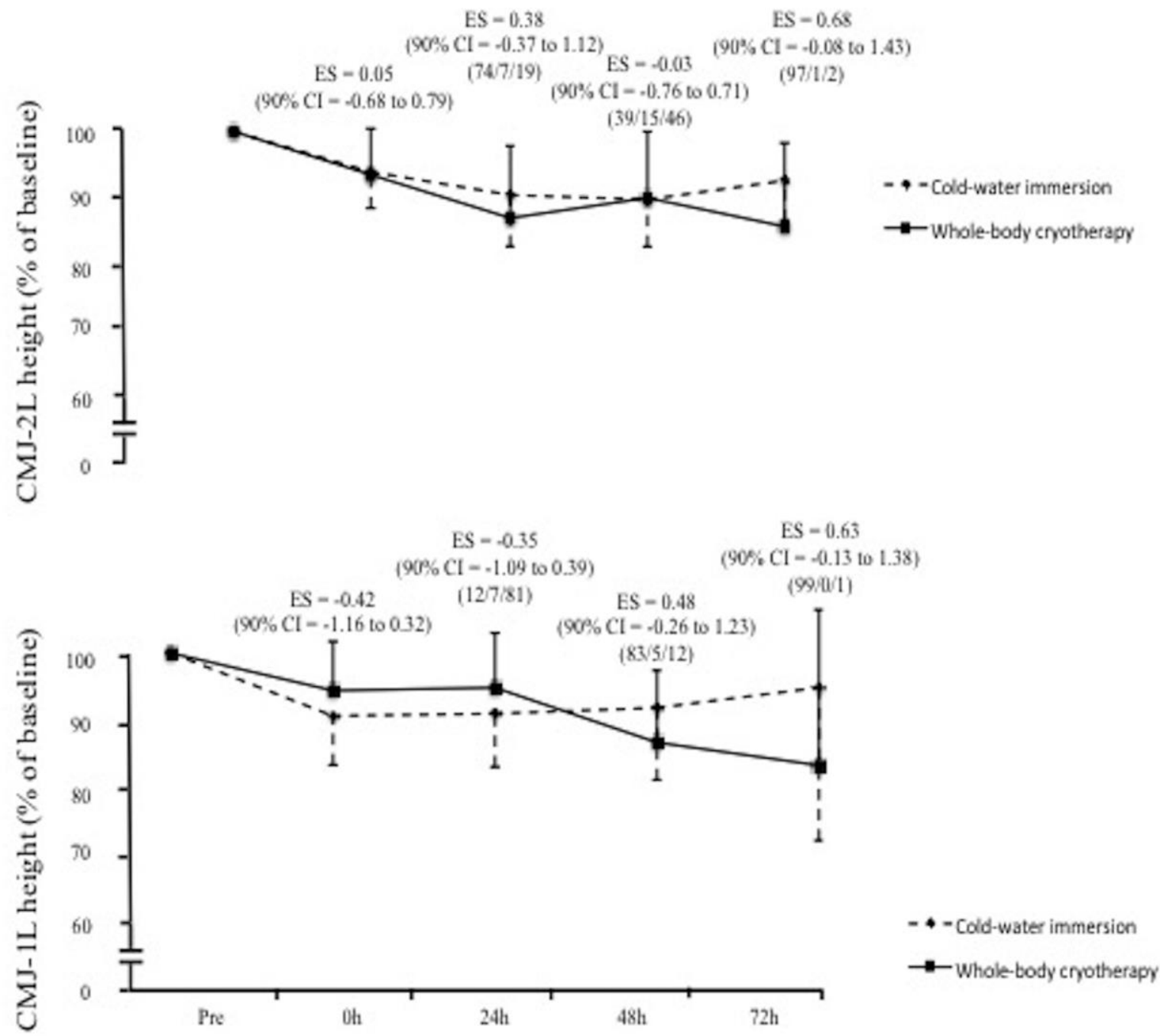

Figure 2: Time-evolution of single-leg (CMJ-1L) and two-legs countermovement jump (CMJ-2L) in the cold-water and whole-body cryotherapy conditions at baseline (Pre), immediately $0 \mathrm{~h}), 24 \mathrm{~h}, 48 \mathrm{~h}$ and $72 \mathrm{~h}$ after the exercise induced muscle damage. ES = effect size between cold-water and whole-body cryotherapy. Probabilities to have an effect are presented as: (cold-water immersion/trivial/whole-body cryotherapy). 
"Recovery From Exercise-Induced Muscle Damage: Cold Water Immersion Versus Whole Body Cryotherapy" by Abaïdia AE et al.

International Journal of Sports Physiology and Performance

(c) 2016 Human Kinetics, Inc.
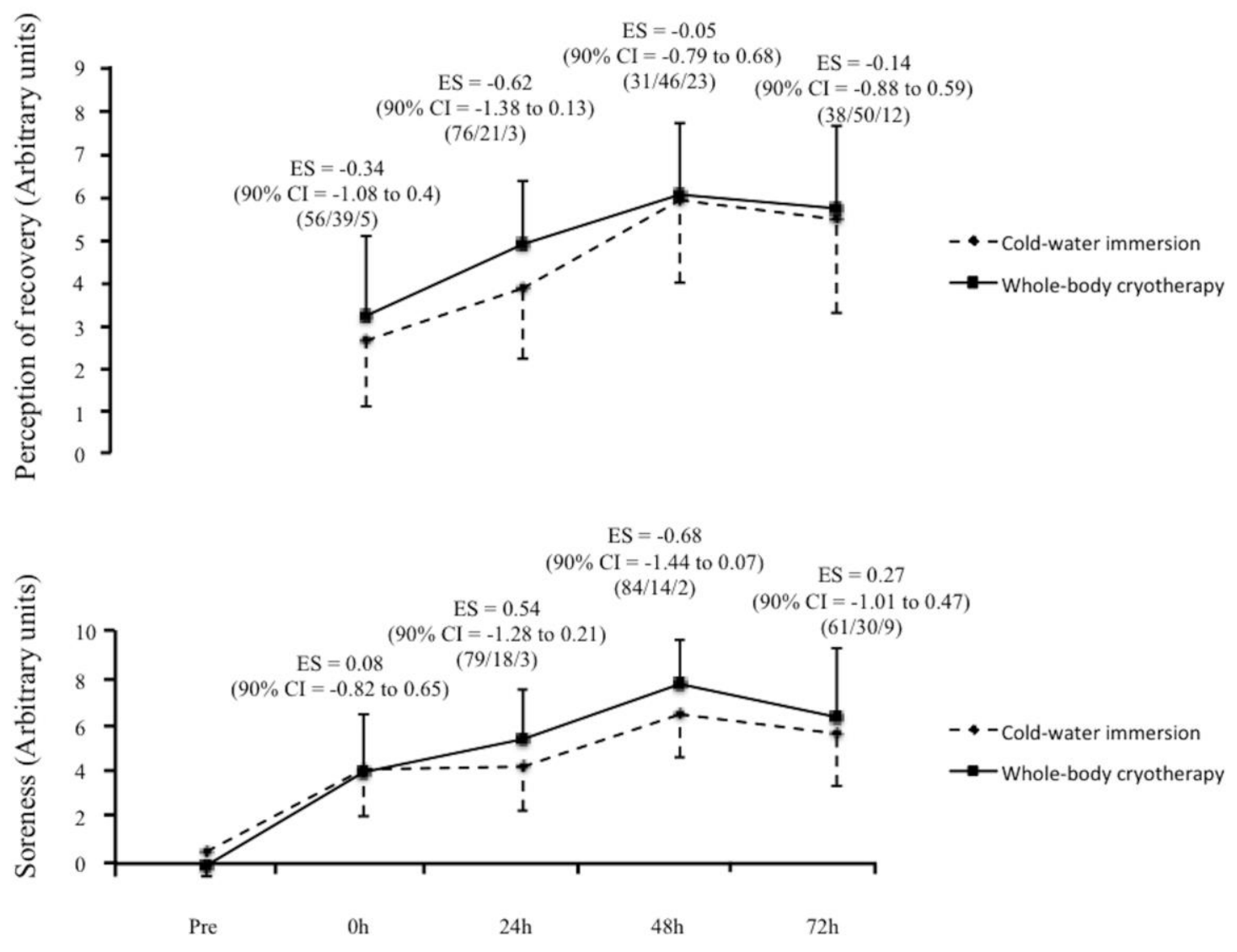

Figure 3: Time-evolution of muscle soreness and perception of recovery in the cold-water and whole-body cryotherapy conditions at baseline (Pre), immediately (0h), 24h, 48h and 72h after the exercise induced muscle damage. ES = effect size between cold-water and wholebody cryotherapy. Probabilities to have an effect are presented as: (cold-water immersion/trivial/whole-body cryotherapy). 
"Recovery From Exercise-Induced Muscle Damage: Cold Water Immersion Versus Whole Body Cryotherapy" by Abaïdia AE et al.

International Journal of Sports Physiology and Performance

(C) 2016 Human Kinetics, Inc.

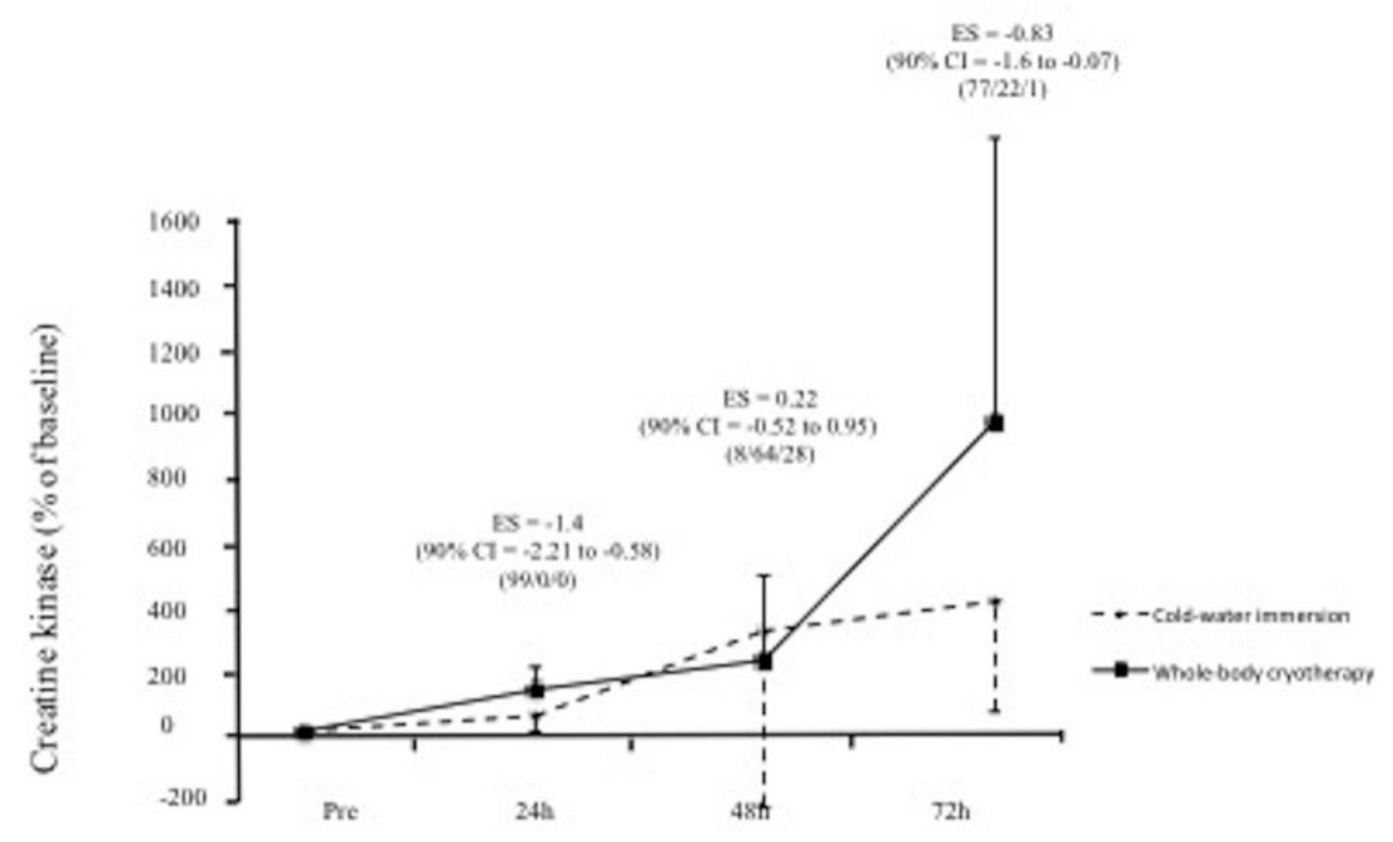

Figure 4: Time-evolution of creatine kinase concentrations in the cold-water and whole-body cryotherapy conditions at baseline (Pre), 24h, 48h and $72 \mathrm{~h}$ after the exercise induced muscle damage. ES = effect size between cold-water and whole-body cryotherapy. Probabilities to have an effect are presented as: (cold-water immersion/trivial/whole-body cryotherapy). 
"Recovery From Exercise-Induced Muscle Damage: Cold Water Immersion Versus Whole Body Cryotherapy" by Abaïdia AE et al.

International Journal of Sports Physiology and Performance

(C) 2016 Human Kinetics, Inc.

Table 1: Reliability of outcomes measured during the experimental protocol.

\begin{tabular}{|c|c|c|c|c|c|c|}
\hline & Trial 1 & Trial 2 & Effect Size $(90 \%$ CI) & $\begin{array}{c}\text { TE } \\
(90 \% \text { CI })\end{array}$ & $\begin{array}{c}\text { ICC } \\
(90 \% \text { CI })\end{array}$ & $\mathbf{C V}$ \\
\hline $\begin{array}{c}\text { Eccentric Force } \\
60^{\circ} \cdot \mathrm{s}^{-1} \\
\left(\mathrm{~N} \cdot \mathrm{m}^{-1}\right)\end{array}$ & $194.7 \pm 29.1$ & $200.5 \pm 44.3$ & $\begin{array}{c}0.15 \\
(90 \% \mathrm{CI}=-0.6 \text { to } 0.9)\end{array}$ & $\begin{array}{c}16.76 \\
(90 \% \mathrm{CI}=12 \text { to } 28.7)\end{array}$ & $\begin{array}{c}0.85 \\
(90 \% \mathrm{CI}=0.6 \text { to } 1)\end{array}$ & $12 \%$ \\
\hline $\begin{array}{c}\text { Isometric Force } \\
\mathbf{6 0}^{\circ} \\
(\mathbf{N})\end{array}$ & $144.2 \pm 26$ & $144.8 \pm 28$ & $\begin{array}{c}0.02 \\
(90 \% \mathrm{CI}=-0.8 \text { to } 0.8)\end{array}$ & $\begin{array}{c}4.05 \\
(90 \% \mathrm{CI}=2.7 \text { to } 7.8)\end{array}$ & $\begin{array}{c}0.98 \\
(90 \% \mathrm{CI}=0.9 \text { to } 1)\end{array}$ & $3.9 \%$ \\
\hline $\begin{array}{c}\text { CMJ-1L } \\
(\mathrm{cm})\end{array}$ & $17.5 \pm 4.2$ & $16.8 \pm 4.6$ & $\begin{array}{c}-0.16 \\
(90 \% \mathrm{CI}=-1.04 \text { to } 0.7) \\
\end{array}$ & $\begin{array}{c}0.85 \\
(90 \% \mathrm{CI}=0.5 \text { to } 2.5) \\
\end{array}$ & $\begin{array}{c}0.97 \\
\text { (90\% CI }=0.8 \text { to } 0.99)\end{array}$ & $9.4 \%$ \\
\hline
\end{tabular}

Trial 1 and trial 2 are respectively the first and second trial performed by the subjects after the familiarization for each outcome concerned. 
"Recovery From Exercise-Induced Muscle Damage: Cold Water Immersion Versus Whole Body Cryotherapy" by Abaïdia AE et al.

International Journal of Sports Physiology and Performance

(C) 2016 Human Kinetics, Inc.

Table 2: Time effect of each outcome in comparison with baseline value.

\begin{tabular}{|c|c|c|c|c|c|}
\hline Outcome & Condition & Oh & $24 \mathrm{~h}$ & $48 \mathrm{~h}$ & 72h \\
\hline & CWI & $\mathrm{ES}=-1.38$ & $\mathrm{ES}=-1.97$ & $\mathrm{ES}=-3.64$ & $\mathrm{ES}=-2.79$ \\
\hline Eccentric & & $(90 \% \mathrm{CI}=-2.2$ to -0.6$)$ & $(90 \% \mathrm{CI}=-2.9$ to -1.1$)$ & $(90 \% \mathrm{CI}=-4.8$ to -2.5$)$ & $(90 \% \mathrm{CI}=-3.8$ to -1.9$)$ \\
\hline $\begin{array}{c}\text { Force } \\
60^{\circ} . \mathbf{s}^{-1} \\
\left(\mathbf{N} \cdot \mathbf{m}^{-1}\right)\end{array}$ & WBC & $\begin{aligned} \mathrm{ES} & =-1.84 \\
(90 \% \mathrm{CI} & =-2.7 \text { to }-1)\end{aligned}$ & $\begin{aligned} \mathrm{ES} & =-1.91 \\
(90 \% \mathrm{CI} & =-2.8 \text { to }-1)\end{aligned}$ & $\begin{aligned} \mathrm{ES} & =-2.23 \\
(90 \% \mathrm{CI} & =-3.2 \text { to }-1.3)\end{aligned}$ & $\begin{aligned} \mathrm{ES} & =-1.51 \\
(90 \% \mathrm{CI} & =-2.3 \text { to }-0.7)\end{aligned}$ \\
\hline \multirow{2}{*}{$\begin{array}{l}\text { Isometric } \\
\text { force } 60^{\circ} \\
(\mathrm{N})\end{array}$} & CWI & $\begin{aligned} \mathrm{ES} & =-4.29 \\
(90 \% \mathrm{CI} & =-5.6 \text { to }-3)\end{aligned}$ & $\begin{aligned} \mathrm{ES} & =-2.71 \\
(90 \% \mathrm{CI} & =-3.7 \text { to }-1.7)\end{aligned}$ & $\begin{array}{c}\mathrm{ES}=-2.8 \\
(90 \% \mathrm{CI}=-3.8 \text { to }-1.8)\end{array}$ & $\begin{aligned} \mathrm{ES} & =-2.79 \\
(90 \% \mathrm{CI} & =-3.8 \text { to }-1.8)\end{aligned}$ \\
\hline & WBC & $\begin{aligned} \mathrm{ES} & =-3.57 \\
(90 \% \mathrm{CI} & =-4.7 \text { to }-2.4)\end{aligned}$ & $\begin{aligned} \mathrm{ES} & =-2.82 \\
(90 \% \mathrm{CI} & =-3.8 \text { to }-1.8)\end{aligned}$ & $\begin{aligned} \mathrm{ES} & =-2.58 \\
(90 \% \mathrm{CI} & =-3.6 \text { to }-1.6)\end{aligned}$ & $\begin{aligned} \mathrm{ES} & =-2.15 \\
(90 \% \mathrm{CI} & =-3.1 \text { to }-1.2)\end{aligned}$ \\
\hline \multirow{2}{*}{$\begin{array}{l}\text { CMJ-2L } \\
(\mathbf{c m})\end{array}$} & CWI & $\begin{aligned} \mathrm{ES} & =-1.47 \\
(90 \% \mathrm{CI} & =-2.3 \text { to }-0.7)\end{aligned}$ & $\begin{aligned} \mathrm{ES} & =-1.72 \\
(90 \% \mathrm{CI} & =-2 \text { to }-0.9)\end{aligned}$ & $\begin{aligned} \mathrm{ES} & =-2.14 \\
(90 \% \mathrm{CI} & =-3.1 \text { to }-1.2)\end{aligned}$ & $\begin{aligned} \mathrm{ES} & =-1.56 \\
(90 \% \mathrm{CI} & =-2.4 \text { to }-0.7)\end{aligned}$ \\
\hline & WBC & $\begin{aligned} \mathrm{ES} & =-1.25 \\
(90 \% \mathrm{CI} & =-2.1 \text { to }-0.5)\end{aligned}$ & $\begin{aligned} \mathrm{ES} & =-1.69 \\
(90 \% \mathrm{CI} & =-2.5 \text { to }-1)\end{aligned}$ & $\begin{aligned} \mathrm{ES} & =-1.43 \\
(90 \% \mathrm{CI} & =-2.3 \text { to }-0.6)\end{aligned}$ & $\begin{aligned} \mathrm{ES} & =-1.57 \\
(90 \% \mathrm{CI} & =-2.4 \text { to }-0.7)\end{aligned}$ \\
\hline \multirow[b]{2}{*}{$\begin{array}{c}\text { CMJ-1L } \\
(\mathbf{c m})\end{array}$} & CWI & $\begin{array}{c}\mathrm{ES}=-1.34 \\
(90 \% \mathrm{CI}=-2.1 \text { to }-0.5)\end{array}$ & $\begin{aligned} \mathrm{ES} & =-1.03 \\
(90 \% \mathrm{CI} & =-1.8 \text { to }-0.3)\end{aligned}$ & $\begin{aligned} \mathrm{ES} & =-1.16 \\
(90 \% \mathrm{CI} & =-2 \text { to }-0.4)\end{aligned}$ & $\begin{aligned} \mathrm{ES} & =-0.53 \\
(90 \% \mathrm{CI} & =-1.3 \text { to } 0.2)\end{aligned}$ \\
\hline & WBC & $\begin{aligned} \mathrm{ES} & =-1.03 \\
(90 \% \mathrm{CI} & =-1.8 \text { to }-0.3)\end{aligned}$ & $\begin{aligned} \mathrm{ES} & =-0.81 \\
(90 \% \mathrm{CI} & =-1.6 \text { to }-0)\end{aligned}$ & $\begin{array}{c}\mathrm{ES}=-1.7 \\
(90 \% \mathrm{CI}=-2.6 \text { to }-0.9)\end{array}$ & $\begin{aligned} \mathrm{ES} & =-1.02 \\
(90 \% \mathrm{CI} & =-1.8 \text { to }-0.3)\end{aligned}$ \\
\hline \multirow[b]{2}{*}{$\begin{array}{l}{[\mathbf{C K}]} \\
\left(\mathbf{U}^{-\mathbf{L}^{-1}}\right)\end{array}$} & CWI & N/A & $\begin{aligned} \mathrm{ES} & =1.33 \\
(90 \% \mathrm{CI} & =0.5 \text { to } 2.1)\end{aligned}$ & $\begin{array}{c}\mathrm{ES}=0.8 \\
(90 \% \mathrm{CI}=0.04 \text { to } 1.6)\end{array}$ & $\begin{aligned} \mathrm{ES} & =1.67 \\
(90 \% \mathrm{CI} & =0.8 \text { to } 2.5)\end{aligned}$ \\
\hline & WBC & N/A & $\begin{aligned} \mathrm{ES} & =2.68 \\
(90 \% \mathrm{CI} & =1.7 \text { to } 3.7)\end{aligned}$ & $\begin{array}{c}\mathrm{ES}=1.17 \\
(90 \% \mathrm{CI}=0.4 \text { to } 2)\end{array}$ & $\begin{aligned} \mathrm{ES} & =1.53 \\
(90 \% \mathrm{CI} & =0.7 \text { to } 2.4)\end{aligned}$ \\
\hline \multirow[b]{2}{*}{$\begin{array}{l}\text { Soreness } \\
(\mathbf{A U})\end{array}$} & CWI & $\begin{aligned} \mathrm{ES} & =2.15 \\
(90 \% \mathrm{CI} & =1.2 \text { to } 3.1)\end{aligned}$ & $\begin{aligned} \mathrm{ES} & =2.35 \\
(90 \% \mathrm{CI} & =1.4 \text { to } 3.3)\end{aligned}$ & $\begin{aligned} \mathrm{ES} & =3.86 \\
(90 \% \mathrm{CI} & =2.7 \text { to } 5.1)\end{aligned}$ & $\begin{aligned} \mathrm{ES} & =2.88 \\
(90 \% \mathrm{CI} & =1.9 \text { to } 3.9)\end{aligned}$ \\
\hline & WBC & $\begin{aligned} \mathrm{ES} & =2.18 \\
(90 \% \mathrm{CI} & =1.3 \text { to } 3.1)\end{aligned}$ & $\begin{array}{c}\mathrm{ES}=3.7 \\
(90 \% \mathrm{CI}=2.5 \text { to } 4.9)\end{array}$ & $\begin{aligned} \mathrm{ES} & =5.88 \\
(90 \% \mathrm{CI} & =4.2 \text { to } 7.5)\end{aligned}$ & $\begin{aligned} \mathrm{ES} & =3.17 \\
(90 \% \mathrm{CI} & =2.1 \text { to } 4.3)\end{aligned}$ \\
\hline \multirow{2}{*}{$\begin{array}{c}\text { Perception } \\
\text { of recovery } \\
\text { (AU) }\end{array}$} & CWI & N/A & $\begin{array}{c}\mathrm{ES}=0.79 \\
(90 \% \mathrm{CI}=0 \text { to } 1.6)\end{array}$ & $\begin{array}{c}\mathrm{ES}=1.88 \\
(90 \% \mathrm{CI}=1 \text { to } 2.8)\end{array}$ & $\begin{aligned} \mathrm{ES} & =1.51 \\
(90 \% \mathrm{CI} & =0.7 \text { to } 2.3)\end{aligned}$ \\
\hline & WBC & N/A & $\begin{aligned} \mathrm{ES} & =0.99 \\
(90 \% \mathrm{CI} & =0.2 \text { to } 1.8)\end{aligned}$ & $\begin{aligned} \mathrm{ES} & =1.61 \\
(90 \% \mathrm{CI} & =0.8 \text { to } 2.5)\end{aligned}$ & $\begin{aligned} \mathrm{ES} & =1.33 \\
(90 \% \mathrm{CI} & =0.5 \text { to } 2.1)\end{aligned}$ \\
\hline
\end{tabular}

$\mathrm{CWI}=$ cold-water immersion. $\mathrm{WBC}=$ whole-body cryotherapy. $[\mathrm{CK}]=$ creatine kinase concentrations. $\mathrm{AU}=$ arbitrary units. This table presents a comparison of each time point mean value with baseline values in each condition. The information given is the time effect of the exercise. The effect sizes (ES) and confidence intervals (CI) represent the difference between a given time point and the baseline value for the considered outcome. 